\title{
Low aerobic mitochondrial energy metabolism in poorly- or undifferentiated neuroblastoma
}

\author{
Rene' G Feichtinger1, Franz Zimmermann', Johannes A Mayr ${ }^{1}$, Daniel Neureiter², Cornelia Hauser-Kronberger², \\ Freimut H Schilling ${ }^{3}$, Neil Jones ${ }^{1}$, Wolfgang Sperl ${ }^{1}$ and Barbara Kofler*1
}

\begin{abstract}
Background: Succinate dehydrogenase (SDH) has been associated with carcinogenesis in pheochromocytoma and paraganglioma. In the present study we investigated components of the oxidative phosphorylation system in human neuroblastoma tissue samples.

Methods: Spectrophotometric measurements, immunohistochemical analysis and Western blot analysis were used to characterize the aerobic mitochondrial energy metabolism in neuroblastomas (NB).

Results: Compared to mitochondrial citrate synthase, SDH activity was severely reduced in NB $(n=14)$ versus kidney tissue. However no pathogenic mutations could be identified in any of the four subunits of SDH. Furthermore, no genetic alterations could be identified in the two novel SDH assembly factors SDHAF1 and SDH5. Alterations in genes encoding nfs-1, frataxin and isd-11 that could lead to a diminished SDH activity have not been detected in NB.

Conclusion: Because downregulation of other complexes of the oxidative phosphorylation system was also observed, a more generalized reduction of mitochondrial respiration seems to be present in neuroblastoma in contrast to the single enzyme defect found in hereditary pheochromocytomas.
\end{abstract}

\section{Background}

According to the International Neuroblastoma (NB) Pathology Classification, NBs are defined as embryonal tumors of the sympathetic nervous system, derive from the neural crest and arise in the adrenal medulla, paravertebral sympathetic ganglia, and sympathetic paraganglia [1]. Paraganglioma and pheochromocytoma are histologically related to NB as they are all neural crest derived. NBs mainly consist of immature neuroblasts, whereas pheochromocytomas and paragangliomas contain mature chromaffin cells.

Pheochromocytomas and paragangliomas frequently exhibit mutations in the succinate dehydrogenase (SDH) subunits SDHB, SDHC, SDHD indicating that these SDH subunits act as tumor suppressors in neuroendocrine tissues [2]. The SDH complex is composed of four subunits and contains a flavin molecule (FAD), non-heme iron centers and a b-type cytochrome as prosthetic groups. The complex is anchored by a large SDHC and a small

* Correspondence: b.kofler@salk.at

1 Department of Pediatrics, University Hospital Salzburg, Paracelsus Medical University, Salzburg, Austria

Full list of author information is available at the end of the article
SDHD subunit that together comprise the membranespanning heme protein cyt $b$ [3]. In addition, two assembly factors of SDH SDHAF1 and SDH5 have been reported recently. SDH5 is a gene required for flavination of SDH [4]. Pathogenic mutations in SDH5 have been identified in paragangliomas [5].

Mutations in the PHOX2B and anaplastic lymphoma kinase (ALK) genes are linked to a predisposition for neuroblastoma [6-10]. Mutations in PHOX2B have been found in a minority of familial neuroblastoma cases. So far no clear link to the energy metabolism has been demonstrated for these two genes.

Mutations in the $V H L$ gene cause von Hippel-Lindau disease, a dominantly inherited familial cancer syndrome predisposing to a variety of malignant and benign neoplasms, including clear cell renal carcinoma and pheochromocytoma [11-13]. Loss of VHL protein in tumors results in an accumulation of hypoxia-inducible factor- $1 \alpha$ (HIF-1 $\alpha$ ) during normoxia. Such accumulation of HIF-1 $\alpha$ in turn induces expression of various genes containing hypoxia-responsive elements, thereby decreasing the expression of components of aerobic energy metabolism 
[14-17]. Accordingly, not only is SDHB protein suppressed in tumors with mutations in SDHB and SDHD, but also in a subset of tumors with VHL mutations which act through HIF1 $\alpha[18,19]$. In addition, alterations of proteins involved in $\mathrm{Fe}-\mathrm{S}$ cluster biogenesis, including Nitrogen fixation-1 homolog (nfs-1), LYR motif containing 4 (LYRM4; isd11), and frataxin, can lead to a reduction of SDH activity [20-24]. For example, disrupted expression of frataxin in murine hepatocytes causes decreased oxidative phosphorylation (OXPHOS) paralleled by reduced activity of iron-sulfur cluster-containing proteins [20]. During the process of OXPHOS ATP is formed as electrons are transferred from NADH or FADH2 to molecular oxygen $(\mathrm{O} 2)$ by a series of electron carriers. The energy released by catabolic biochemical processes, such as glycolysis, citric acid cycle, and fatty acid oxidation is stored as the reduced coenzymes NADH or FADH2. There is a step by step transfer of electrons from NADH or FADH2 to specific protein complexes, which are part of the electron transport chain. Electrons are transferred from these reduced equivalents, through the electron transport chain (ETC), to $\mathrm{O}_{2}$. The ETC consists of four multisubunit complexes namely complex I - IV. SDH is both part of the ETC as well as the citric acid cycle. The liberated energy is used to create a proton gradient over the inner mitochondrial membrane. In the final reaction of OXPHOS, the reflux of protons is used by the complex $\mathrm{V}$ (ATP synthase) to produce ATP.

The aerobic use of glucose as an energy source through glycolysis is a feature common to most solid tumors, in turn leading to a lesser dependence on OXPHOS, which is called the Warburg effect $[25,26]$. The downregulation of OXPHOS in tumor cells seems to be achieved by different mechanisms. First, profound hypoxia can be the cause of compensatory upregulation of glycolysis in most tumors. Secondly, it is becoming more and more evident that the loss of tumor suppressor genes such as $V H L$ and $p 53$ or activation of oncogenes results in downregulation of OXPHOS $[27,28]$. Finally, direct inactivation of components of OXPHOS has been detected in a minority of tumors. Besides the association of SDH and tumor development, loss of NADH: ubiquinone oxidoreductase (complex I) of the respiratory chain has also been shown in oxiphilic tumors $[29,30]$.

The aim of the present study was to determine if there are specific alterations of aerobic energy metabolism in $\mathrm{NBs}$, especially of SDH, or if there is an overall downregulation of OXPHOS complexes.

Although it is generally accepted that solid cancers exhibit in most cases a shift from oxidative phosphorylation to glycolysis the type of alteration has not been investigated in many types of cancers, and to our knowledge not in neuroblastic tumors.

\section{Methods}

\section{Samples}

NBs from 14 patients were obtained from the University Hospital Salzburg, Austria and the Olga Hospital, Stuttgart, Germany. Fifteen unaffected kidney tissues served as references for enzymatic measurements. For immunohistochemical studies formalin fixed, paraffin embedded NBs and unaffected adrenal tissues were used.

The study was performed according to the Austrian Gene Technology Act. Experiments were performed in accordance with the Helsinki declaration of 1975 (revised 1983) and the guidelines of the Salzburg State Ethics Research Committee (ethical agreement: AZ 209-11-E1/ 823-2006) being no clinical drug trial or epidemiological investigation. All patients have signed an informed consent concerning the surgical removal and therapy of the tumors. Furthermore the study did not extend to examination of individual case records. The anonymity of the patients has been ensured.

All tissues were frozen and stored in liquid nitrogen within 30 min after surgery. Tumor cell content and cellular composition of samples were evaluated using hematoxylin-eosin-stained frozen sections. Tissue samples with a tumor cell content of over $90 \%$ were investigated. Poorly differentiated or undifferentiated tumor tissues were used in the study (Table 1).

\section{Enzyme measurements}

NB and kidney tissues (20-100 mg) were homogenized with a tissue disintegrator (Ultraturrax, IKA, Staufen, Germany) in extraction buffer ( $20 \mathrm{mM}$ Tris- $\mathrm{HCl}, \mathrm{pH} 7.6$, $250 \mathrm{mM}$ sucrose, $40 \mathrm{mM} \mathrm{KCl}, 2 \mathrm{mM}$ EGTA) and finally homogenized with a motor-driven Teflon-glass homogenizer (Potter S, Braun, Melsungen, Germany). The homogenate was centrifuged at $600 \mathrm{~g}$ for $10 \mathrm{~min}$ at $4^{\circ} \mathrm{C}$. The postnuclear supernatant (600 $g$ homogenate) containing the mitochondrial fraction was used for measurement of enzyme activities and Western blot analysis. Citrate synthase was determined according to Srere [31] with modifications. Briefly, the reaction mixture contained $50 \mathrm{mM}$ Tris- $\mathrm{HCl} \mathrm{pH} \mathrm{8.1,} \mathrm{0.1 \%} \mathrm{bovine} \mathrm{serum} \mathrm{albumin} \mathrm{(BSA),} \mathrm{0.1 \%}$ TritonX-100, $0.2 \mathrm{mM}$ 5,5'-dithio-bis(2-nitrobenzoic acid), $0.15 \mathrm{mM}$ acetyl-CoA and the $600 \mathrm{~g}$ homogenate. After initially recording thiolase activity for $2 \mathrm{~min}$ the citrate synthase reaction was started by addition of $0.5 \mathrm{mM}$ oxaloacetate and was followed at $412 \mathrm{~nm}$ for $8 \mathrm{~min}$. The mean unspecific thiolase activity in NBs was $2 \%$ of the CS activity.

Enzyme activities of the OXPHOS complexes were determined as previously described [32,33]. Briefly, rotenone-sensitive complex I activity was measured spectrophotometrically as NADH/decylubiquinone oxidoreductase at $340 \mathrm{~nm}$. The enzyme activities of citrate synthase and complex IV (ferrocytochrome c/oxygen 
Table 1: Clinical characteristics of neuroblastoma patients and tumor tissues.

\begin{tabular}{|c|c|c|c|c|c|c|c|c|c|}
\hline Patient & Sex & $\begin{array}{c}\text { Age } \\
\text { [months] }\end{array}$ & Stage & $\begin{array}{c}\text { Differen } \\
\text { tiation }\end{array}$ & n-myc & $1 p$ del & ploidy & PHOX2B & ALK \\
\hline 1 & $\mathrm{~F}$ & 31 & 4 & u.d. & neg & neg & $2 n$ & neg & n.c. \\
\hline 2 & $M$ & 3 & $2 \mathrm{~A}$ & u.d. & neg & neg & $3 n$ & neg & n.c. \\
\hline 3 & M & 3 & $4 S$ & u.d. & neg & neg & $3 n$ & neg & n.c. \\
\hline 4 & M & 11 & 1 & u.d. & neg & neg & $3 n$ & neg & n.c. \\
\hline 5 & M & 11 & $2 B$ & u.d. & pos & pos & $3 n / 4 n$ & neg & n.c. \\
\hline 6 & M & 15 & $2 B$ & u.d. & neg & neg & $3 n$ & neg & n.c. \\
\hline 7 & $F$ & 142 & 4 & u.d. & neg & neg & $3 n$ & neg & neg \\
\hline 8 & $F$ & 1 & 3 & u.d. & neg & neg & $3 n$ & neg & neg \\
\hline 9 & M & 7 & $3 \mathrm{~A}$ & u.d. & neg & neg & $3 n$ & neg & n.c. \\
\hline 10 & $F$ & 10 & $4 S$ & p.d. & neg & neg & $2 n$ & neg & n.c. \\
\hline 11 & $M$ & 11 & 1 & u.d. & neg & n.d. & n.d. & neg & neg \\
\hline 12 & $\mathrm{~F}$ & 166 & 4 & u.d. & neg & neg & $3 n$ & neg & neg \\
\hline 13 & M & 2 & 1 & u.d. & neg & neg & n.d & neg & n.c. \\
\hline 14 & M & 5 & 1 & u.d. & neg & neg & $3 n$ & neg & n.c. \\
\hline
\end{tabular}

u.d.: undifferentiated; p.d.: poorly differentiated; n.d.: not determined; $n$-myc neg: no n-myc amplification; n-myc pos: $n$-myc amplification; PHO2B neg: no mutation; ALK neg: no ALK mutation, n.c.: no cDNA available

oxidoreductase), and the oligomycin-sensitive ATPase activity of the $\mathrm{F}_{1} \mathrm{~F}_{0}$ ATP synthase were determined by using buffer conditions as previously described by Rustin et al. (1994) [34]. The whole reaction mixture for the ATPase activity measurement was treated for 10 seconds with an ultra-sonifier (Bio cell disruptor 250, Branson, Vienna, Austria). SDH activity was measured according to Rustin et al. with the following modifications. The reaction mixture contained $50 \mathrm{mM}$ potassium phosphate pH 7.8, 2 mM EDTA, 0.1\% BSA, $3 \mu \mathrm{M}$ rotenone, $80 \mu \mathrm{M}$ 2,6-dichlorophenol, $50 \mu \mathrm{M}$ decylubiquinone, $1 \mu \mathrm{M}$ antimycin A, $0.2 \mathrm{mM}$ ATP, $0.3 \mathrm{mM} \mathrm{KCN}$ and the $600 \mathrm{~g}$ homogenate. The mixture was preincubated for $10 \mathrm{~min}$ at $37^{\circ} \mathrm{C}$, started by addition of $10 \mathrm{mM}$ succinate, and followed for $6 \mathrm{~min}$ at $600 \mathrm{~nm}$.

The reaction mixture for the measurement of the complex III activity contained $50 \mathrm{mM}$ potassium phosphate buffer $\mathrm{pH}$ 7.8, 2 mM EDTA pH 8.6, 0.3 mM KCN, $100 \mu \mathrm{M}$ cytochrome c, $200 \mu \mathrm{M}$ reduced decyl-ubiquinol. The reaction was started by addition of the $600 \mathrm{~g}$ homogenate. After $3-4$ min the reaction was inhibited by addition of 1 $\mu \mathrm{M}$ antimycin A. Antimycin A- insensitive activity was substracted from total activity to calculate complex III activity. All spectrophotometric measurements (Uvicon 922, Kontron, Milan, Italy) were performed at $37^{\circ} \mathrm{C}$.

Sequencing of SDHA, SDHB, SDHC, SDHD, SDHAF1, SDH5, nfs-1, LYRM4, frataxin, PHOX2B and ALK

DNA was isolated using a NucleoSpin ${ }^{\circ}$ Tissue Kit (Macherey-Nagel). RNA was isolated from cryosections of NB tissues using Tri-Reagent ${ }^{\text {tw }}$ (Molecular Research Center Inc., Cincinnati, OH). $2 \mu \mathrm{g}$ of RNA were treated with DNase I (Ambion, Austin, TX) and reverse-transcribed with 140 U Superscript II reverse transcriptase (Invitrogen Corporation, Carlsbad, CA) according to the manufacturer's instructions. $100 \mathrm{ng}$ genomic DNA (for sequencing of SDHB, SDHC, SDHD, SDHAF1, SDH5, PHOX2B) or cDNA (for sequencing of SDHA, frataxin, nfs1, LYRM4, ALK) were used for the PCR amplification (Table 2). PCR products were incubated with Exo SAP IT 500 (USB Corporation), and the CEQ DTCS Quickstart Kit (Beckman Coulter) was used for the sequencing reaction using the PCR primers listed in Table 2, followed by separation with a CEQ 2000 DNA Analysis System (Beckman Coulter).

\section{Determination of the mtDNA copy number}

The mtDNA copy number was determined as previously described [35].

\section{Western blot analysis}

$600 \mathrm{~g}$ homogenates were used for Western blot analysis. After protein quantification (Pierce BCA Protein Assay), a total of $5 \mu \mathrm{g}$ protein was separated on $10 \%$ acrylamide/ bisacrylamide gels and transferred to nitrocellulose membranes (Amersham Biosciences; Hybond ${ }^{\mathrm{m}}$-C Extra) using a CAPS buffer (10 mM 3-[cyclohexylamino]-1-propane sulfonic acid, $\mathrm{pH} 11 ; 10 \%$ methanol). The membranes were washed in Tris-buffered saline buffer (TBS, $\mathrm{pH}$ 7.4) for $5 \mathrm{~min}$, air-dried for $30 \mathrm{~min}$, washed $10 \mathrm{~min}$ in TBS and 
Table 2: Primers used for PCR and sequencing.

\begin{tabular}{|c|c|c|c|c|}
\hline & forward primer 5'-3' & reverse primer 5'-3' & bp & Ref-sequ. \\
\hline SDHA fragment $1^{*}$ & GCGAAGGACCTGGCGTCTA & CCCAGAGTGCAGAAGCGTAT & 1100 & NM 004168.2 \\
\hline SDHA fragment 2 & GACTGCGCGGCGGCAACA & CAGCCTCTTCCTTCTCGGAT & 1094 & NM 004168.2 \\
\hline SDHB Exon 1 & GGGTCCTCAGTGGATGTAGGCT & GCCTTGCCCTATGCTTCCTC & 272 & NM 003000.2 \\
\hline SDHB Exon 2 & GAATGCCTGCCTITCTAAGAAGA & GCCATCGGATGATCTCAGATTIT & 377 & NM 003000.2 \\
\hline SDHB Exon 3 & CCTGAGAAGACCAAATGGATAAGC & AGCTGCAGCTGTTTTCCAGATG & 300 & NM 003000.2 \\
\hline SDHB Exon 4 & TGTTGCATGTCAGTGCTGCCC & GGTCCTCCTCCTGCCATAATATAGG & 423 & NM 003000.2 \\
\hline SDHB Exon 5 & CGAGTAGTCAGTGTCCAAGAAATGG & AATGGCTTGCATCAGCTTATGTTC & 317 & NM 003000.2 \\
\hline SDHB Exon 6 & TITGTTCATGCACTGACCCCA & AAACCAGGCCCCTCAGAATG & 307 & NM 003000.2 \\
\hline SDHB Exon 7 & TGAATTCCCTTTCCTCTGCACTC & ATGACTAGGGTTGCTCTCTGCCA & 323 & NM 003000.2 \\
\hline SDHB Exon 8 & TTGCTTGGACACTGAACCAGCT & GCTGTATTCATGGAAAACCAAGATC & 286 & NM 003000.2 \\
\hline SDHC Exon 1 & GCGTCACTTCCGTCCAGACC & CTGCCCAGGCACAGGATAAA & 150 & NM $003001 . .3$ \\
\hline SDHC Exon 2 & СССТТСАССССTAAAAATAGAGAAG & AAAATAATCTCCAGGGCCGGG & 480 & NM $003001 . .3$ \\
\hline SDHC Exon 3 & CCTGGCTTGGTATTGCAAAATATTG & AAGGGTTCACCTCATCTACATAGCA & 336 & NM $003001 . .3$ \\
\hline SDHC Exon 4 & ACCTATTCAGGAGAATTGCTTGGA & ATCAAGTGCTGAGTTTCAAAGGAGG & 382 & NM $003001 . .3$ \\
\hline SDHC Exon 5 & TGGTTTAGAATTGTATGAGGTGCCA & GCGAGACTCCACTCTTGGGAA & 387 & NM $003001 . .3$ \\
\hline SDHC Exon 6 & CGCTITTCTCTAGAATCATGCTGAG & TCTACTGCTCCAAGGAGATCTGAAA & 375 & NM $003001 . .3$ \\
\hline SDHD Exon 1 & CCAGCATTTCCTCTTCCCTGTT & CTCCTCAAGAGATCTCCCACCC & 252 & NM 003002.1 \\
\hline SDHD Exon 2 & TGGTCTTAACTTCACAGTAACCCCA & GGTCTTCATTTGACAAAGTTGGACA & 413 & NM 003002.1 \\
\hline SDHD Exon 3 & TGTACACTGCCTGTCAGTTTGGG & TAGGGCATTTCAATCAACTTCTCCC & 345 & NM 003002.1 \\
\hline SDHD Exon 4 & GGAGACATTGCATTGAACTTGACA & AAAGCAGAGGCAAAGAGGCATACAT & 334 & NM 003002.1 \\
\hline LYRM4 & TCGTACTTGGGACCTCGGCGAA & TGGATGCTGAAGGTGGTCCCTG & 379 & NM 020408.3 \\
\hline Nfs1 fragment 1 & TGCTCCTCAGTCTGCGGTT & CCCCTTTGGGACCGTAGATT & 686 & NM 021100 \\
\hline $\mathrm{Nfs} 1$ fragment 2 & TCCATACTGATGCAGCCCA & CCAATCTAGAGCATCCACTAGG & 789 & NM 021100 \\
\hline Frataxin fragment 1 & ACATCGATGCGACCTGCAC & TGACACATAGCCCAACTGTCC & 638 & NM 181425.1 \\
\hline Frataxin fragment 2 & GCAGAGGAAACGCTGGACT & TGACACATAGCCCAACTGTCC & 478 & NM 181425.1 \\
\hline ALK fragment 1 & GCTGGGTACCAAGGACTGTTCA & CTGGTTCCTGAGGTCATGCAGT & 957 & CCDS37172.1 \\
\hline ALK fragment 2 & AAGACTCCTTCCCTTTCCTGTCTC & AAGGACACGTTTCCCCTCAAGA & 949 & CCDS37172.1 \\
\hline ALK fragment 3 & GTTCCAGGACCACCAAGACCAT & AAATACGTAGGTGGCTCCACCC & 955 & CCDS37172.1 \\
\hline ALK fragment 4 & CCTGCCCCAGTACAAACCAGTT & GCAGTAGTTGGGGTTGTAGTCGGT & 947 & CCDS37172.1 \\
\hline ALK fragment 5 & CTGGCTTTCTCCGGCATCAT & CCTGTCTTCAGGCTGATGTTGC & 972 & CCDS37172.1 \\
\hline ALK fragment 6 & CTTGGATATATGCCATACCCCAGC & GTTTGTGAAGGAGCCATTGCCT & 970 & CCDS37172.1 \\
\hline PHOX2B Exon 1 & CTCCAGCCACCTTCTCCATA & TTCCTATATACGGGCGGAAA & 369 & NC 000004.11 \\
\hline PHOX2B Exon2 & CAGCTTCTCTCGGCAACTCT & GGCCCTAGGTCCTTCTCACT & 426 & NC 000004.11 \\
\hline PHOX2B Exon3 & ACCCTAACCGGTGCTTTTCT & ACAATAGCCTTGGGCCTACC & 686 & NC 000004.11 \\
\hline SDHAF1 & CTGAGCGTCTCTGCTTAGCC & СTCTGACATCCCCAATTCGT & 506 & NM 001042631.1 \\
\hline SDH5-fragment 1 & GTTTCCGGTGCAGGTGGG & GCACACAGTAGGCTCACCAA & 251 & NM 017841.1 \\
\hline SDH5-fragment 2 & CCTGGCCACAGTGTAATTT & TCAAATCAGCCTAAACTGTCCT & 675 & NM 017841.1 \\
\hline SDH5-fragment 3 & GTGGTTCTTGGCCAGTGTT & GCAAGGCTAACGTCCATCAT & 297 & NM 017841.1 \\
\hline
\end{tabular}

*SDHA fragment 1 was sequenced additionally with the following reverse primer: TCCGTCATGTAGTGGATGGC. bp: fragment length in base pairs. Ref-sequ.: GenBank-reference sequence. 
blocked $1 \mathrm{~h}$ at room temperature (RT) in 5\% fat-free milk powder dissolved in TBS. After washing with TBS- $0.1 \%$ Tween 20, the membranes were incubated with the primary antibody solutions. Primary antibodies were diluted in 5\% fat-free milk powder dissolved in TBS. The following primary antibody dilutions and incubation times were used: monoclonal mouse anti-SDHA $70 \mathrm{kD}$ antibody (1:15 000, 2 h, RT); MitoSciences, Eugene, OR), monoclonal mouse anti-Core 2 antibody (1:2000, $2 \mathrm{~h}$, RT; MitoSciences), polyclonal rabbit anti-GAPDH antibody (1:5000, $1 \mathrm{~h}, \mathrm{RT}$; Trevigen), polyclonal goat anti-VHL antibody (1:10 000, overnight, $4^{\circ} \mathrm{C}$; Everest). After washing, the membranes were incubated with secondary antibodies as follows: SDHA $70 \mathrm{kD}$ and Core 2 blots, $2 \mathrm{~h}$ with polyclonal antimouse IgG POD-labeled antibody 1:400

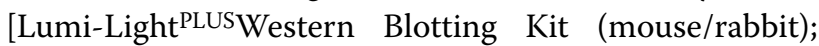
Roche] at RT; GAPDH $1 \mathrm{~h}$ with polyclonal anti-rabbit IgG POD-labeled antibody 1:1000 [Lumi-Light ${ }^{\text {PLUSWestern }}$ Blotting Kit (mouse/rabbit); Roche] at RT; VHL $1 \mathrm{~h}$ with polyclonal anti-goat IgG antibody 1:5000 (Dako, Glostrup, Denmark) at RT. Detection was carried out

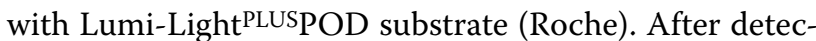
tion of SDHA $70 \mathrm{kD}$ and Core 2 the nitrocellulose membranes were washed twice in stripping buffer $(25 \mathrm{mM}$ glycine- $\mathrm{HCl}, \mathrm{pH} 2,2 \% \mathrm{SDS}$ ) for $15 \mathrm{~min}$, and a subsequent immunodetection with GAPDH antibody was performed as described above. Subsequently, the same stripping procedure was used prior to detection of VHL.

\section{Immunohistochemical staining and analysis}

Formalin-fixed and paraffin-embedded tumor tissues were used. For immunohistochemical staining the following antibodies were used: mouse monoclonal anti-complex II subunit $70 \mathrm{kDa} F \mathrm{Fp}$ (1:5000; MitoSciences), mouse monoclonal anti-complex III subunit Core 2 (1:1500; MitoSciences), and mouse monoclonal anti-porin 31HL (1:3000; MitoSciences) antibodies. All antibodies were diluted in Dako antibody diluent with background reducing components (Dako).

$5 \mu \mathrm{m}$ sections were deparaffinized and rehydrated, followed by heat-induced epitope retrieval in TE-T buffer (10 mM Tris base, pH 9.0, 1 mM EDTA, 0.05\% Tween 20) for $40 \mathrm{~min}$ at $95^{\circ} \mathrm{C}$ and $20 \mathrm{~min}$ at RT. Sections were washed in distilled $\mathrm{H}_{2} \mathrm{O}$ and equilibrated with phosphatebuffered saline containing $0.5 \%$ Tween 20 (pH 7.4, PBS$\mathrm{T})$. Staining was performed using an Envision Detection System (Dako) according to manufacturer's instructions, followed by visualization with diaminobenzidine (DAB) for $1 \mathrm{~min}$. Slides were counterstained with hematoxylin.

\section{Results}

Characteristics of the 14 pediatric patients and their NB tumors are given in Table 1. The activity of citrate synthase was comparably high in normal cortical kidney tis- sues and NBs (Figure 1). Moreover, the level of citrate synthase activity was in accordance with the level of porin as determined by immunohistochemical staining. Both citrate synthase and porin are frequently used as marker proteins for mitochondrial mass. The NBs showed only a slight reduction of porin compared to normal adrenal cortex and adrenal medulla tissue (Figure 2). Therefore, the mitochondrial masses of the NBs and normal renal tissues were similar.

As pheochromocytomas and NB originate from neural crest and pheochromocytomas frequently show reduced SDH activity caused by pathogenic SDH mutations, we measured the enzymatic activity of SDH in NB. We decided to compare OXPHOS enzyme activities of NB with cortical kidney tissues since it is not possible to isolate a sufficient amount of foetal neural crest cells for enzymatic measurements. In addition, the activity of citric synthase in NB tissues and normal kidney tissues does not differ significantly. The NB samples $(\mathrm{n}=14)$ showed a mean residual SDH activity of $11 \pm 12 \%$ compared to unaffected kidney cortex tissue $(\mathrm{n}=14)$ (Figure. 1). Immunohistochemical staining of SDH in NB underlined these results (Figure 2b, e, h).

To evaluate if this massive downregulation of SDH in NB is due to a mutation in one of the four nuclearencoded SDH subunits, we sequenced the SDH genes. Sequencing of five NB samples did not reveal any pathogenic mutation in the SDH genes. All SNPs were silent mutations. The single nucleotide polymorphism (SNP) rs1126417 was found in three of five NBs. Two of the five NBs carried the SNP rs36097930. In addition, a new nucleotide substitution, c.1948A $>$ G p.Asn650Asp, was detected in three NB samples in SDHA. The amino acid residue shows only weak conservation, but has not been published in the NCBI SNP database. The reference sequences that were used for the alignment are listed in Table 2. In addition no mutations in SDHAF1 and SDH5 were found $(\mathrm{n}=14)$.

Because low SDH activity can be caused by downregulation of iron-sulfur subunits $[21,22]$ we also sequenced nfs-1, LYRM4, frataxin ( $\mathrm{n}=7$ ) for pathogenic mutations. However, no sequence variations were found in comparison to the reference sequences.

To ensure that the neuroblastoma-predispostion genes are not associated with the observed downregulation of OXPHOS in our patients, ALK $(\mathrm{n}=4)$ and PHOX2B $(\mathrm{n}=$ 14) was sequenced, but no pathogenic mutations were detected.

Suppressed SDHB protein can be found in pheochromocytomas with loss of VHL $[19,36]$. Immunoblotting revealed that VHL protein was not reduced in NB tissues compared to kidney tissues (Figure 3 ).

Because the investigated NBs had no pathogenic SDH mutations and the amount of the VHL protein was unaf- 
fected, we evaluated the enzymatic activities of the other OXPHOS complexes in comparison to normal kidney tissue. All enzyme activities were significantly lower in NB compared to kidney tissue (Table 3). Relative to citrate synthase activity, we found mean residual activities of complex I ( $23 \pm 16 \%)$, complex III ( $74 \pm 28 \%)$, complex IV (COX) $(28 \pm 14 \%)$, and ATP synthase $(20 \pm 17 \%)$ in NB tissues (Figure 1). There was no significant difference in enzyme activities when correlated to ploidy or stage of the NBs (data not shown).

Western blot analysis of SDH and complex III was in agreement with the overall downregulation of OXPHOS complexes in NB (Figure 3). In addition, immunohistochemical analysis showed a reduction of complex II and complex III in NB compared to unaffected adrenal cortex and medulla (Figure 2).

The mtDNA copy number was significantly reduced in NBs $(n=14)$ compared to cortical kidney tissues $(n=10)$ (Figure 1g).

\section{Discussion}

NB showed a massive reduction in SDH activity compared to normal cortical kidney tissues. Sequencing demonstrated that the observed downregulation of SDH activity is not due to pathogenic mutations in the genes encoding the SDH subunits. These findings are in agreement with previous studies which also failed to detect pathogenic mutations in $S D H B$ or $S D H D$ [37,38]. $S D H B$ maps to chromosome $1 \mathrm{p} 36$, a region of frequent loss of heterozygosity (LOH) in NB (Martinsson et al. 1997). Astuti et al. (2004) could not provide evidence for epigenetic inactivation of the $S D H B$ gene promoter [37]. Accordingly, our sample with a $1 \mathrm{p} 36$ deletion (patient 5, Table 1) did not differ in OXPHOS activity compared to the 1 pdel negative samples.

Mutations in the assembly factors SDHAF1 and SDH5 could also be excluded to be the cause of the observed phenotype. Furthermore, on the basis of our data the two major NB predisposition genes can be excluded to lead to the reduction of the OXPHOS enzyme activities in NBs. Although NBs and pheochromocytomas share a common origin, carcinogenesis in NBs is not linked to pathogenic $V H L$ mutations, as in a subset of pheochromocytomas [39]. Deletions of the short arm of chromosome 3 are often observed in a specific subset of aggressive NBs. The critical deleted region encompasses the $V H L$ locus. Hoebeeck et al. (2006) demonstrated that reduced VHL mRNA expression is a poor prognostic indicator for NB. The reduced expression of the $V H L$ gene suggests that $V H L$ could act in a haploinsufficient manner [40]. Because we detected no differences in the amount of VHL protein between NB and normal kidney samples, our data suggest that VHL is not involved in downregulation of OXPHOS in the NB samples investigated.
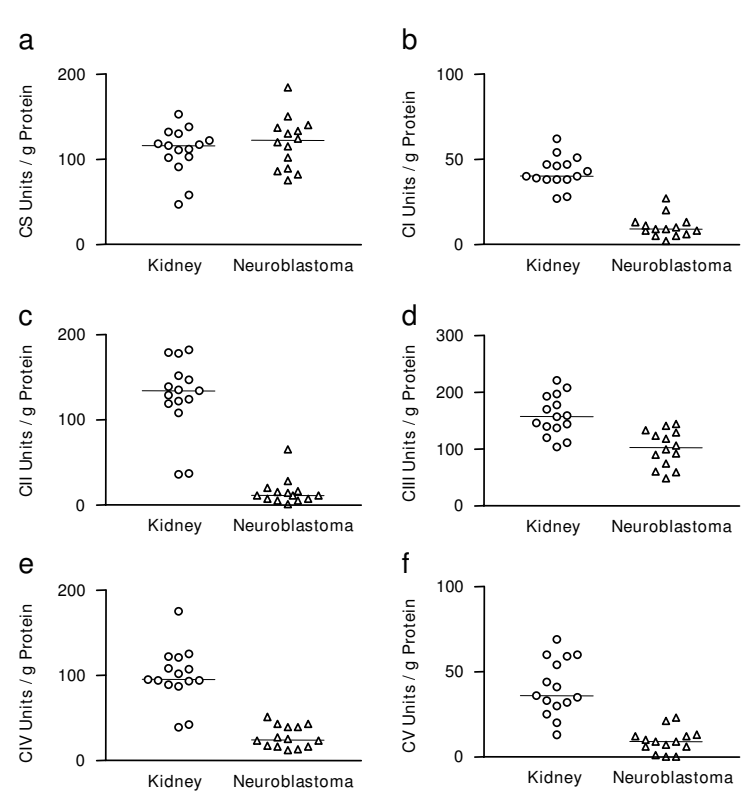

g

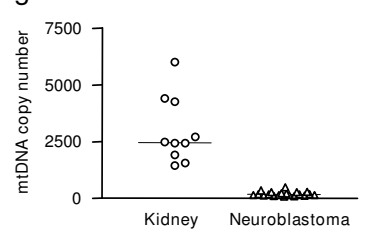

Figure 1 Activity of OXPHOS complexes in normal kidney tissues and NBs. a: citrate synthase (CS), b: complex I (Cl), c: complex II (CII), d: complex III (CIII), e: complex IV (CIV), f: complex V (CV), g: mtDNA copy number.

Correct incorporation of the Fe-S cluster into SDH is a prerequisite for the functionality of the SDH protein, and downregulation of proteins involved in Fe-S cluster biogenesis could lead to diminished SDH activity. However, we were not able to detect mutations in the Fe-S cluster biogenesis genes frataxin, $n f s-1$ and LYRM4. Since frataxin, $\mathrm{nfs}-1$ and isd 11 are only three proteins of the ISC (iron sulfur cluster) machinery, it can not be excluded that a mutation in one of the other proteins involved in ISC biogenesis is responsible for the massive impairment of the SDH activity in NB.

Alterations of ISC proteins also lead to a reduction of complexes I and III. The measurements of the enzymatic activities of complex I, complex III, complex IV and ATP synthase indicate an overall downregulation of the aerobic energy metabolism in NB. Because complex IV and complex $\mathrm{V}$ possess no Fe-S clusters, the reduction of complex IV and complex $\mathrm{V}$ activity can not be related to a defect of an ISC assembly protein.

The significant reduction of the mtDNA copy number in NBs could explain a reduction of OXPHOS complexes with exception of SDH, which is nuclear encoded. Therefore, the phenotype from NBs differs from that in classi- 

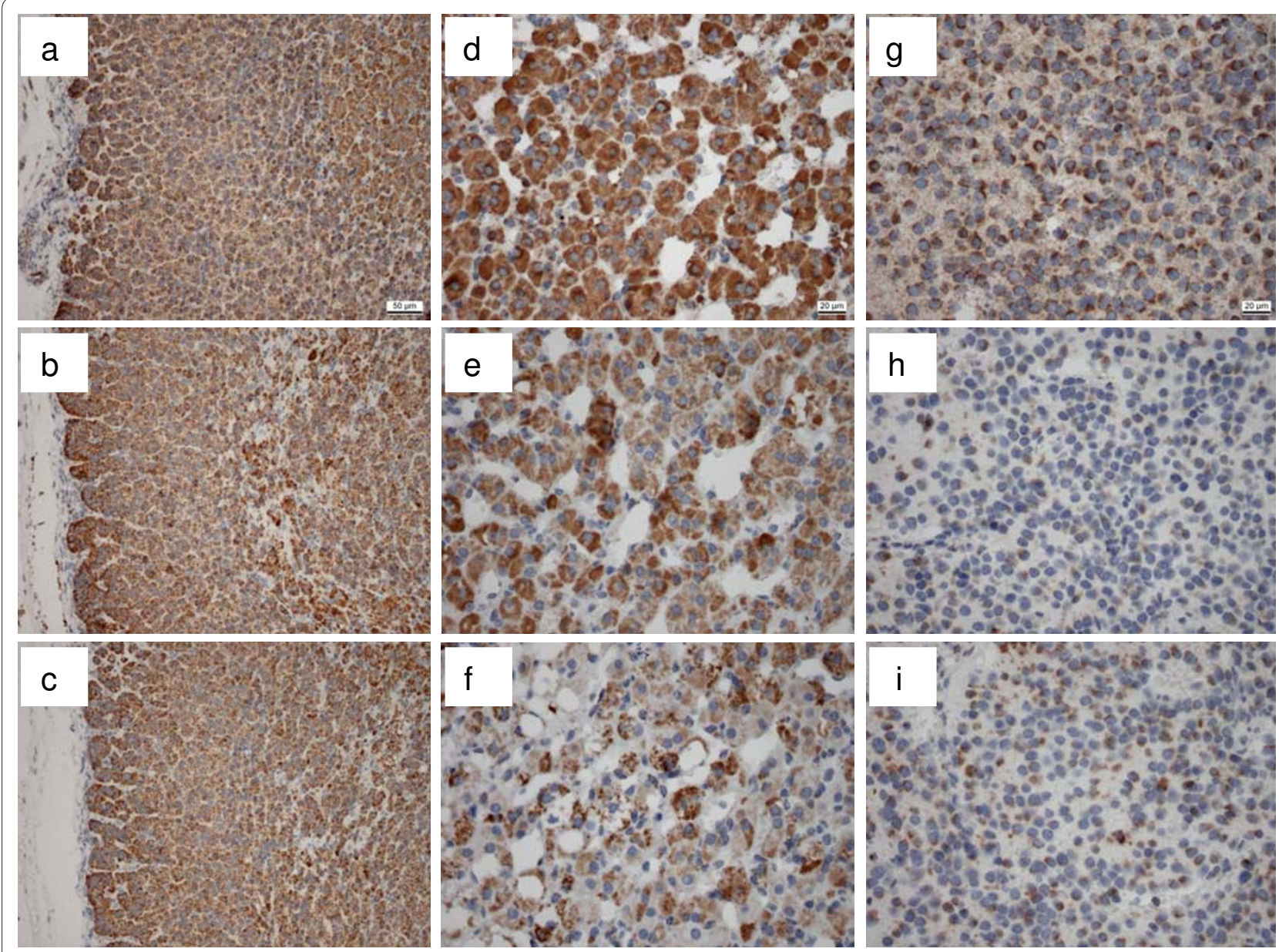

Figure 2 Immunohistochemical staining of porin, complex II and complex III of NB, adjacent adrenal cortex and adrenal medulla. Immunohistochemical staining of porin ( $a, d, g)$, complex II subunit $70 \mathrm{kDa} \mathrm{Fp}(b, e, h)$ and complex III subunit Core2 $(c, f, i)$ in unaffected adrenal tissue $(a, b, c)$ and unaffected adrenal medulla ( $d, e, f)$ was compared to the adjacent NB tumor tissue ( $g$, h, i). Magnification: Figure 2a - c 200x, Figure 2d - i 400x.

cal depletion syndromes where high SDH activities can be detected.

The observed overall reduction of activity of the enzymes of the OXPHOS system is not due to downregulation of mitochondrial mass, because measurement of citrate synthase and staining of porin revealed that NBs and control kidney samples possess equal amounts of mitochondria. We have used normal kidney as a refer-

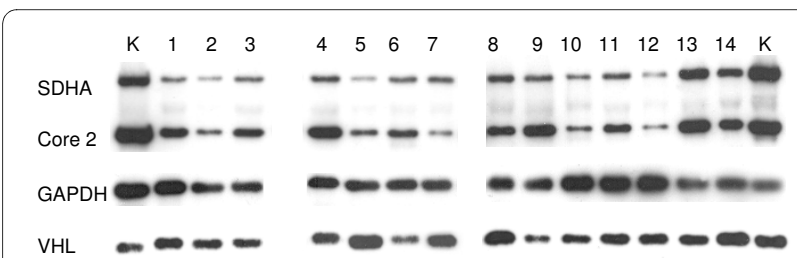

Figure 3 Western blot analysis of NBs and kidney tissue samples. Complex II (SDHA; subunit 70 kDa Fp), Complex III (subunit Core 2), GAPDH, VHL. Lane K: normal kidney cortex tissue, lanes 1-14 NB samples. ence because this tissue has comparable citrate synthase activity to NBs. In order to conclude that NB tumor cells have downregulated OXPHOS components, the cell type from which the tumor originates has to be analyzed. Because we were not able to get enough normal adrenal tissue for enzymatic analysis, we performed an immunohistochemical analysis on normal adrenal tissue and were able to show that cells of the adrenal cortex and medulla did indeed have substantial staining of porin, complex II and complex III. This indicates clearly the loss of OXPHOS during tumor transformation and progression. We are aware of the limitation of the comparison of NBs to adjacent adrenal tissue since NBs are derived from primordial neural crest cells which can not be detected in postnatal adrenal cortex and medulla.

\section{Conclusion}

In summary the molecular mechanisms leading to OXPHOS impairment in pheochromocytomas and neuroblastomas differ between these two tumor entities. In 
Table 3: Enzyme activity of the complexes of the OXPHOS system.

\begin{tabular}{|c|c|c|c|}
\hline & Kidney $(n=15) *$ & Tumor $(n=14)^{*}$ & P value \\
\hline $\begin{array}{l}\text { Citrate synthase [mUnits/mg } \\
\text { protein] }\end{array}$ & $110 \pm 7$ & $119 \pm 8$ & 0.4088 \\
\hline $\begin{array}{l}\text { Complex I [mUnits/mg } \\
\text { protein] }\end{array}$ & $43 \pm 2$ & $10 \pm 2$ & $<0.0001$ \\
\hline Complex I/citrate synthase & $0.40 \pm 0.02$ & $0.09 \pm 0.02$ & $<0.0001$ \\
\hline $\begin{array}{l}\text { Complex II [mUnits/mg } \\
\text { protein] }\end{array}$ & $128 \pm 11$ & $15 \pm 4$ & $<0.0001$ \\
\hline Complex II/citrate synthase & $1.13 \pm 0.06$ & $0.14 \pm 0.04$ & $<0.0001$ \\
\hline $\begin{array}{l}\text { Complex III [mUnits/mg } \\
\text { protein] }\end{array}$ & $159 \pm 9$ & $101 \pm 9$ & $<0.0001$ \\
\hline Complex III/citrate synthase & $1.50 \pm 0.09$ & $0.92 \pm 0.11$ & 0.0002 \\
\hline $\begin{array}{l}\text { Complex IV [mUnits/mg } \\
\text { protein] }\end{array}$ & $100 \pm 8$ & $28 \pm 3$ & $<0.0001$ \\
\hline Complex IV/citrate synthase & $0.90 \pm 0.05$ & $0.25 \pm 0.03$ & $<0.0001$ \\
\hline $\begin{array}{l}\text { ATP synthase [mUnits/mg } \\
\text { protein] }\end{array}$ & $41 \pm 4$ & $9 \pm 2$ & $<0.0001$ \\
\hline ATP synthase/citrate synthase & $0.38 \pm 0.04$ & $0.08 \pm 0.02$ & $<0.0001$ \\
\hline mtDNA copy number & $2960 \pm 431$ & $194 \pm 22$ & $<0.0001$ \\
\hline
\end{tabular}

*Values are given as mean \pm SD

NB there are no pathogenic mutations in SDH subunits present and there is not a single enzyme deficiency, but there is downregulation of all components of the aerobic mitochondrial energy metabolism without affecting mitochondrial mass.

Knowledge of the mechanism of tumor cells to achieve the Warburg effect provides the basics for functional studies to recover the aerobic energy metabolism as a potential new therapeutic strategy to threat malignancies.

\begin{abstract}
Abbreviations
ALK: anaplastic lymphoma kinase; BCA: bicinchoninic acid; BSA: bovine serum albumin; CAPS: 3-[cyclohexylamino]-1-propane sulfonic acid; COX: cytochrome c oxidase; ECT: electron transport chain; FAD: flavin adenine dinucleotide; GAPDH: glyceraldehyde-3-phosphate dehydrogenase; HIF-1a: hypoxia-inducible factor-1a; ISC: iron sulphur cluster; LYRM4: LYR motif containing 4; NB: neuroblastoma; nfs-1: nitrogen fixation-1 homologue; OXPHOS: oxidative phosphorylation; SDH: succinate dehydrogenase; SNPs: single nucleotide polymorphisms; VHL: von Hippel Lindau.
\end{abstract}

\section{Competing interests}

The authors declare that they have no competing interests.

\section{Authors' contributions}

RGF carried out the enzymatic measurements and immunohistochemical staining of the NB. RGF and FZ performed the immunoblot anaysis. DN analyzed the immunohistochemical stainings. CHK determined the tumor cell content of the samples. BK and JAM did the conception and design of the study. FHS, NJ and DN provided the NB tissues. RGF and BK drafted the manuscript. JAM and WS critically revised the manuscript for intellectual content. JAM, WS, NJ, BK and RGF interpreted the data. All authors read and approved the manuscript.

\section{Acknowledgements}

This work was supported by the Medizinische Forschungsgesellschaft Salzburg and the Children's Cancer Foundation Salzburg.

\section{Author Details}

1Department of Pediatrics, University Hospital Salzburg, Paracelsus Medical University, Salzburg, Austria, 2Department of Pathology, University Hospital Salzburg, Paracelsus Medical University, Salzburg, Austria and ${ }^{3}$ Department of Pediatric Oncology and Hematology, Olga Hospital, Stuttgart, Germany

Received: 29 July 2009 Accepted: 19 April 2010

Published: 19 April 2010

\section{References}

1. Shimada H, Ambros IM, Dehner LP, Hata J, Joshi W, Roald B, Stram DO Gerbing RB, Lukens JN, Matthay KK, Castleberry RP: The International Neuroblastoma Pathology Classification (the Shimada system). Cancer 1999, 86:364-372.

2. Briere JJ, Favier J, Gimenez-Roqueplo AP, Rustin P: Tricarboxylic acid cycle dysfunction as a cause of human diseases and tumor formation. Am J Physiol Cell Physiol 2006, 291:C1114-1120.

3. Hagerhall C: Succinate: quinone oxidoreductases. Variations on a conserved theme. Biochim Biophys Acta 1997, 1320:107-141.

4. Hao HX, Khalimonchuk O, Schraders M, Dephoure N, Bayley JP, Kunst H, Devilee P, Cremers CW, Schiffman JD, Bentz BG, et al: SDH5, a gene required for flavination of succinate dehydrogenase, is mutated in paraganglioma. Science 2009, 325:1139-1142.

5. Kaelin WG Jr: SDH5 mutations and familial paraganglioma: somewhere Warburg is smiling. Cancer Cell 2009, 16:180-182.

6. George RE, Sanda T, Hanna M, Frohling S, Luther W, Zhang J, Ahn Y, Zhou W, London WB, McGrady P, et al:: Activating mutations in ALK provide a therapeutic target in neuroblastoma. Nature 2008, 455:975-978.

7. Janoueix-Lerosey I, Lequin D, Brugieres L, Ribeiro A, de Pontual L, Combaret V, Raynal V, Puisieux A, Schleiermacher G, Pierron G, et al: Somatic and germline activating mutations of the ALK kinase receptor in neuroblastoma. Nature 2008, 455:967-970. 
8. Mosse YP, Laudenslager M, Khazi D, Carlisle AJ, Winter CL, Rappaport E, Maris JM: Germline PHOX2B mutation in hereditary neuroblastoma. Am J Hum Genet 2004, 75:727-730.

9. Mosse YP, Laudenslager M, Longo L, Cole KA, Wood A, Attiyeh EF, Laquaglia MJ, Sennett R, Lynch JE, Perri P, et al.: Identification of ALK as a major familial neuroblastoma predisposition gene. Nature 2008, 455:930-935.

10. Chen Y, Takita J, Choi YL, Kato M, Ohira M, Sanada M, Wang L, Soda M, Kikuchi A, Igarashi T, et al:: Oncogenic mutations of ALK kinase in neuroblastoma. Nature 2008, 455:971-974.

11. Maher ER, Iselius L, Yates JR, Littler M, Benjamin C, Harris R, Sampson J, Williams A, Ferguson-Smith MA, Morton N: Von Hippel-Lindau disease: a genetic study. J Med Genet 1991, 28:443-447.

12. Shuin T, Kondo K, Torigoe S, Kishida T, Kubota Y, Hosaka M, Nagashima Y, Kitamura H, Latif F, Zbar B, et al.: Frequent somatic mutations and loss of heterozygosity of the von Hippel-Lindau tumor suppressor gene in primary human renal cell carcinomas. Cancer Res 1994, 54:2852-2855.

13. Kanno H, Kondo K, Ito S, Yamamoto I, Fujii S, Torigoe S, Sakai N, Hosaka M, Shuin T, Yao M: Somatic mutations of the von Hippel-Lindau tumor suppressor gene in sporadic central nervous system hemangioblastomas. Cancer Res 1994, 54:4845-4847.

14. Wizigmann-Voos S, Breier G, Risau W, Plate KH: Up-regulation of vascular endothelial growth factor and its receptors in von Hippel-Lindau disease-associated and sporadic hemangioblastomas. Cancer Res 1995, 55:1358-1364

15. Los M, Aarsman CJ, Terpstra L, Wittebol-Post D, Lips CJ, Blijham GH, Voest EE: Elevated ocular levels of vascular endothelial growth factor in patients with von Hippel-Lindau disease. Ann Oncol 1997, 8:1015-1022.

16. Iliopoulos O, Levy AP, Jiang C, Kaelin WG Jr, Goldberg MA: Negative regulation of hypoxia-inducible genes by the von Hippel-Lindau protein. Proc Natl Acad Sci USA 1996, 93:10595-10599.

17. Lonergan KM, Iliopoulos O, Ohh M, Kamura T, Conaway RC, Conaway JW, Kaelin WG Jr: Regulation of hypoxia-inducible mRNAs by the von Hippel-Lindau tumor suppressor protein requires binding to complexes containing elongins B/C and Cul2. Mol Cell Biol 1998 18:732-741.

18. Dahia PL: Transcription association of VHL and SDH mutations link hypoxia and oxidoreductase signals in pheochromocytomas. Ann NY Acad Sci 2006, 1073:208-220.

19. Dahia PL, Ross KN, Wright ME, Hayashida CY, Santagata S, Barontini M, Kung AL, Sanso G, Powers JF, Tischler AS, et al: A HIF1alpha regulatory loop links hypoxia and mitochondrial signals in pheochromocytomas. PLoS Genet 2005, 1:72-80.

20. Thierbach R, Schulz TJ, Isken F, Voigt A, Mietzner B, Drewes G, von KleistRetzow JC, Wiesner RJ, Magnuson MA, Puccio H, et al:: Targeted disruption of hepatic frataxin expression causes impaired mitochondrial function, decreased life span and tumor growth in mice. Hum Mol Genet 2005, 14:3857-3864.

21. Lill R, Dutkiewicz R, Elsasser HP, Hausmann A, Netz DJ, Pierik AJ, Stehling O, Urzica E, Muhlenhoff $\mathrm{U}$ : Mechanisms of iron-sulfur protein maturation in mitochondria, cytosol and nucleus of eukaryotes. Biochim Biophys Acta 2006, 1763:652-667.

22. Lill R, Muhlenhoff U: Iron-sulfur protein biogenesis in eukaryotes: components and mechanisms. Annu Rev Cell Dev Biol 2006, 22:457-486.

23. Biederbick A, Stehling O, Rosser R, Niggemeyer B, Nakai Y, Elsasser HP, Lil $\mathrm{R}$ : Role of human mitochondrial Nfs1 in cytosolic iron-sulfur protein biogenesis and iron regulation. Mol Cell Biol 2006, 26:5675-5687.

24. Wiedemann N, Urzica E, Guiard B, Muller H, Lohaus C, Meyer HE, Ryan MT, Meisinger C, Muhlenhoff $U$, Lill R, Pfanner N: Essential role of Isd1 1 in mitochondrial iron-sulfur cluster synthesis on Isu scaffold proteins. Embo J 2006, 25:184-195.

25. Pedersen PL: Tumor mitochondria and the bioenergetics of cancer cells. Prog Exp Tumor Res 1978, 22:190-274.

26. Racker $E$, Spector M: Warburg effect revisited: merger of biochemistry and molecular biology. Science 1981, 213:303-307.

27. Matoba S, Kang JG, Patino WD, Wragg A, Boehm M, Gavrilova O, Hurley PJ, Bunz F, Hwang PM: p53 regulates mitochondrial respiration. Science 2006, 312:1650-1653.

28. Zhang H, Gao P, Fukuda R, Kumar G, Krishnamachary B, Zeller KI, Dang CV, Semenza GL: HIF-1 inhibits mitochondrial biogenesis and cellular respiration in VHL-deficient renal cell carcinoma by repression of CMYC activity. Cancer Cell 2007, 11:407-420
29. Mayr JA, Meierhofer D, Zimmermann F, Feichtinger R, Kogler C, Ratschek M, Schmeller N, Sperl W, Kofler B: Loss of complex I due to mitochondrial DNA mutations in renal oncocytoma. Clin Cancer Res 2008, 14:2270-2275

30. Gasparre G, Porcelli AM, Bonora E, Pennisi LF, Toller M, lommarini L, Ghell A, Moretti M, Betts CM, Martinelli GN, et al: Disruptive mitochondrial DNA mutations in complex I subunits are markers of oncocytic phenotype in thyroid tumors. Proc Natl Acad Sci USA 2007, 104:9001-9006.

31. Srere PA: Citrate synthase. Methods in enzymology 1969, 13:3-5.

32. Berger A, Mayr JA, Meierhofer D, Fotschl U, Bittner R, Budka H, Grethen C, Huemer M, Kofler B, Sperl W: Severe depletion of mitochondrial DNA in spinal muscular atrophy. Acta Neuropathol 2003, 105:245-251.

33. Meierhofer D, Mayr JA, Foetschl U, Berger A, Fink K, Schmeller N, Hacker GW, Hauser-Kronberger C, Kofler B, Sperl W: Decrease of mitochondrial DNA content and energy metabolism in renal cell carcinoma. Carcinogenesis 2004, 25:1005-1010

34. Rustin P, Chretien D, Bourgeron T, Gerard B, Rotig A, Saudubray JM, Munnich $A$ : Biochemical and molecular investigations in respiratory chain deficiencies. Clin Chim Acta 1994, 228:35-51.

35. Acham-Roschitz B, Plecko B, Lindbichler F, Bittner R, Mache CJ, Sperl W, Mayr JA: A novel mutation of the RRM2B gene in an infant with early fatal encephalomyopathy, central hypomyelination, and tubulopathy. Mol Genet Metab 2009, 98:300-304

36. Guzy RD, Sharma B, Bell E, Chandel NS, Schumacker PT: Loss of the SdhB, but Not the SdhA, subunit of complex II triggers reactive oxygen species-dependent hypoxia-inducible factor activation and tumorigenesis. Mol Cell Biol 2008, 28:718-731.

37. Astuti D, Morris M, Krona C, Abel F, Gentle D, Martinsson T, Kogner P, Neumann HP, Voutilainen R, Eng C, et al.: Investigation of the role of SDHB inactivation in sporadic phaeochromocytoma and neuroblastoma. Br J Cancer 2004, 91:1835-1841.

38. De Preter K, Vandesompele J, Hoebeeck J, Vandenbroecke C, Smet J, Nuyts A, Laureys G, Combaret V, Van Roy N, Roels F, et al:: No evidence for involvement of SDHD in neuroblastoma pathogenesis. BMC Cancer 2004, 4:55.

39. Brauch H, Hoeppner W, Jahnig H, Wohl T, Engelhardt D, Spelsberg F, Ritter MM: Sporadic pheochromocytomas are rarely associated with germline mutations in the vhl tumor suppressor gene or the ret protooncogene. J Clin Endocrinol Metab 1997, 82:4101-4104.

40. Hoebeeck J, Vandesompele J, Nilsson H, De Preter K, Van Roy N, De Smet E, Yigit N, De Paepe A, Laureys G, Pahlman S, Speleman F: The von HippelLindau tumor suppressor gene expression level has prognostic value in neuroblastoma. Int J Cancer 2006, 119:624-629.

\section{Pre-publication history}

The pre-publication history for this paper can be accessed here: http://www.biomedcentral.com/1471-2407/10/149/prepub

doi: 10.1186/1471-2407-10-149

Cite this article as: Feichtinger et al., Low aerobic mitochondrial energy metabolism in poorly- or undifferentiated neuroblastoma BMC Cancer 2010, 10:149

\section{Submit your next manuscript to BioMed Centra and take full advantage of:}

- Convenient online submission

- Thorough peer review

- No space constraints or color figure charges

- Immediate publication on acceptance

- Inclusion in PubMed, CAS, Scopus and Google Scholar

- Research which is freely available for redistribution 